\title{
Postmastectomy Pain Syndrome: A Frequent Problem Facing Cancer Surgeons
}

\author{
Emad Hokkam ${ }^{1}$, , Aly Saber $^{2}$, Taha Moati ${ }^{1}$, Mostafa El-Dosoki ${ }^{2}$ \\ ${ }^{1}$ Department of Surgery, Faculty of Medicine, Suez Canal University, Ismailia, Egypt \\ ${ }^{2}$ Department of Surgery, Port-Fouad General Hospital, Port-Fouad, Egypt
}

Email address:

ehokkam@gmail.com (E. Hokkam)

\section{Tocitethisarticle:}

Emad Hokkam, Aly Saber, Taha Moati, Mostafa El-Dosoki. Postmastectomy Pain Syndrome: A Frequent Problem Facing Cancer Surgeons. Journal of Surgery. Special Issue: Postoperative Pain Syndrome. Vol. 3, No. 2-1, 2015, pp. 18-22. doi: 10.11648/j.js.s.2015030201.14

\begin{abstract}
Background: Post mastectomy pain syndrome (PMPS) is a type of neurogenic pain that persists for a long period after surgery for breast cancer. The present study aims to find out the prevalence of this syndrome and investigate its contributing risk factors. Methods: A descriptive cross-sectional study was carried out among 167womenoperated for breast cancer. Patients with either modified radical mastectomy(MRM) or breast conserving therapy (BTC) were enrolled in the study. Detailed medical history with special emphasis on the presence of pain and its characteristics, duration and location were performed to all patients. Full clinical examination was also performed to exclude other possible causes of pain. All expected risk factors were traced and correlated to the patient condition. Reviewing of medical records of all patients was performed to find out operation details, tumor stage and way of management of axillary lymph nodes. Results: Eighty seven (52\%) out of the 167 studied women reported PMPS. The mean age was $54 \pm 18.3$ years. The incidence of PMPS was more evident in younger age group and in women with advanced tumor stage. There is significant decrease in the incidence of PMPS in patients underwent sentinel lymph node biopsy (SLNB) (Chi-2=4.10 \& P-value=0.043). Moderate and severe pain were most commonly reported among patients underwent MRM while mild pain was most commonly reported among patients underwent BCT (Chi-2=17.51 \& P-value=0.001). Intercostobrachial neuralgia was the most commonly reported type of pain among patients underwent MRM and patients underwent BCT (Chi-2=10.47 \& P-value=0.015). Pain occurred more frequently at the shoulder, axilla and arm complex (48.3\%). Conclusion: PMPS is an evident problem. Cancer surgeons should clearly identify patients who are at risk aiming to minimize or even eliminate the chance of developing this syndrome.
\end{abstract}

Keywords: Breast cancer, mastectomy, pain.

\section{Introduction}

Breast cancer is the most common cause of cancer-related death among women worldwide. In Egypt, carcinoma of the breast is the most prevalent cancer among Egyptian women and constitutes $29 \%$ of National Cancer Institute cases and most patients are premenopausal. In most cases, breast cancer is treated surgically. Despite the efficiency of the surgical treatment of breast cancer, several complications have been reported; chronic postoperative pain is one of the most frequent and important of these complications ${ }^{(1-4)}$.

Chronic pain has been reported after all types of surgery for breast cancer (mastectomy, quadrantectomy, wide local excision.....etc). It is not uncommon phenomenon. Several reports have suggested that it may affect up to $50 \%$ or more of women following breast surgeries performed for malignancy ${ }^{(2,5)}$.The syndrome was first reported in the decade of $1970 \mathrm{~s}$ by $\mathrm{Wood}^{(6)}$, and it is defined by the International Association for Study of Pain (IASP) as chronic pain in the anterior aspect of the thorax, axilla, and/or upper half of the arm beginning after mastectomy or quadrantectomy and persisting for more than three months after the surgery ${ }^{(7)}$.

The exact mechanism of PMPS is not known ${ }^{(8,9)}$, but it is probably a neuropathic pain condition, that caused by damage to nerves in the axilla and/or the chest wall during surgery ${ }^{(8,10)}$. On this basis, an alternative term, intercostobrachial neuralgia, has been proposed ${ }^{(8,10,11)}$. Other causes for chronic pain after treatment for breast cancer include radiotherapy, chemotherapy, axillary haematoma and secondary neuroma formation ${ }^{(10,12)}$.

PMPS can develop shortly after surgery or up to several months after it and can persist for years. Like other 
neuropathic pain conditions, the treatment is often difficult. Recent studies suggested that prognosis of PMPS is better than expected, with a decline in the prevalence over years $(8,13,14)$. Proposed main risk factors are: young age, sectioning of the intercostobrachial nerve and axillary dissection. Dissection of axillary lymph nodes has been shown a critical component in the aetiology of chronic pain after surgery for breast cancer. The frequency of this procedure has been reduced over the past few years, due to evolution of the concept of SLNB. Thus, the prevalence of PMPS may have decreased ${ }^{(15-20)}$. The study aims to determine the current prevalence of PMPS and to identify its risk factors.

\section{Patients and Methods}

This study was carried out as a descriptive cross-sectional study. Over a 18 month period (between August 2010 and January 2012); a total of 167 female patients operated for breast cancer were recruited during their follow up visits at the outpatient clinic of General Surgery Department and Oncology Department at Suez Canal University Hospital, Ismailia, Egypt.

Patients with either MRM or BCT were included in the study. We used three criteria when defining PMPS: character, location and timing of pain ${ }^{(9)}$. As regards the character; common features of neuropathic pain including sense of burning or stabbing, numbness, tingling or needles were considered $^{(4,13)}$. The location of pain should be at shoulder, axilla, ipsilateral arm or anterior chest wall ${ }^{10,21)}$. The pain should be persisting either continuously or intermittently for longer than the normal healing time of 3 months ${ }^{(7)}$. The intensity of pain was measured using the Visual Analogue Scale (VAS). VAS has been used as a standard scale for rating pain. The reliability and validity of this scale among other pain scales has been accepted ${ }^{(22)}$.

Exclusion criteria included patients with recurrent malignancy or distant metastasis, patients with postoperative wound infection, patients with persistent seromas, those who did not finish their radiotherapy or chemotherapy yet, patient with chest pain due to other causes rather than surgery (eg; cardiac causes) and patients with any previous psychiatric problem.

All of the included patients were subjected to detailed medical history with special concern to characteristics, duration and location of pain. Full clinical examination was performed to all recruited patients with special emphasis on cardiac, abdominal and chest examination to exclude other causes of chest pain. All expected risk factors were traced and correlated to the patient condition. Reviewing of medical records of all patients was performed to find out the type of surgery, tumor stage and type axillary approach. A questionnaire was introduced to those patients who are suffering pain. It included questions about factors that might increase pain and limit their daily activities.

Gathered data were processed using SPSS version 20 (SPSS Inc., Chicago, IL, USA). Quantitative data were expressed as means $\pm \mathrm{SD}$ while qualitative data were expressed as numbers and percentages (\%). Unpaired t test was used to test significance of difference for quantitative variables while Chi Square test was used to test significance of difference for qualitative variables. A probability value ( $\mathrm{p}$ value $)<0.05$ was considered statistically significant. The study design was approved by the local research ethics committee at faculty of medicine Suez Canal University while an informed consent was obtained from each patient before inclusion into the study.

\section{Results}

Eighty seven (52\%) out of the 167 studied women reported PMPS since operation time and 80 patients $(48 \%)$ did not experience PMPS. Most women were currently married (74\%) and more than quarter of responding women $(26 \%)$ were living alone, a factor that probably makes the problem more worse, as these patients don't have a partner who can give them physical and emotional support. About half of the studied women have a job, and chronic pain may affect their ability of working and their quality of life. Table (1) shows the sociodemograhic characteristics of the studied patients.

Table 1. Patient characteristics

\begin{tabular}{llll}
\hline Patient characteristics & total & With pain & Without pain \\
\hline $\begin{array}{l}\text { Number of patients } \\
\text { Mean age in years (35-74) }\end{array}$ & 167 & $87(52 \%)$ & $80(48 \%)$ \\
Menopausal status: & $54 \mathrm{ys}$ & $50 \mathrm{ys}$ & $58 \mathrm{ys}$ \\
Pre-menopausal & $40(24 \%)$ & 28 & 12 \\
Post-menopausal & $127(76 \%)$ & 59 & 68 \\
Job: & & & \\
Employed & $51(30.5 \%)$ & 31 & 20 \\
House wife & $47(28 \%)$ & 22 & 25 \\
Worker & $32(19 \%)$ & 19 & 13 \\
Retired & $37(22 \%)$ & 15 & 22 \\
Marital status: & & & \\
Married & $124(74 \%)$ & 64 & 60 \\
Single & $5(3 \%)$ & 2 & 3 \\
Widowed & $28(17 \%)$ & 15 & 13 \\
Divorced & $10(6 \%)$ & 6 & 4 \\
\hline
\end{tabular}

The mean age of the included patients was $54 \pm 18.3$ years. We classified them into four age groups. Group A (35 - 44 years old, mean $=41 \mathrm{ys} \pm 3.2$ ), Group B (45 - 54 years old, mean $=50 \mathrm{ys} \pm 2.8)$, Group $\mathrm{C}:(55-64$ years old, mean $=$ $58 \mathrm{ys} \pm 3.4)$ and Group D (65 - 74 years old, mean $=67 \mathrm{ys} \pm$ 2.3). The incidence of PMPS was most evident in group $A$ $($ Chi-2 $=26.87 \&$ P-value $=0.001)$ (Table 2). There is significant increase in the incidence of PMPS with advanced tumor stage $(\mathrm{Chi}-2=13.64 \&$ P-value=0.003). The more advanced tumor stage, the greater the incidence of PMPS. (Figure 1)

Table 2. The incidence of PMPS among different age groups

\begin{tabular}{llll}
\hline Age group & With pain (87) & Without pain (80) & Total (167) \\
\hline A & $27(75 \%)$ & $9(25 \%)$ & 36 \\
B & $43(63 \%)$ & $25(37 \%)$ & 68 \\
C & $12(27 \%)$ & $32(73 \%)$ & 44 \\
D & $5(26 \%)$ & $14(74 \%)$ & 19 \\
\hline
\end{tabular}




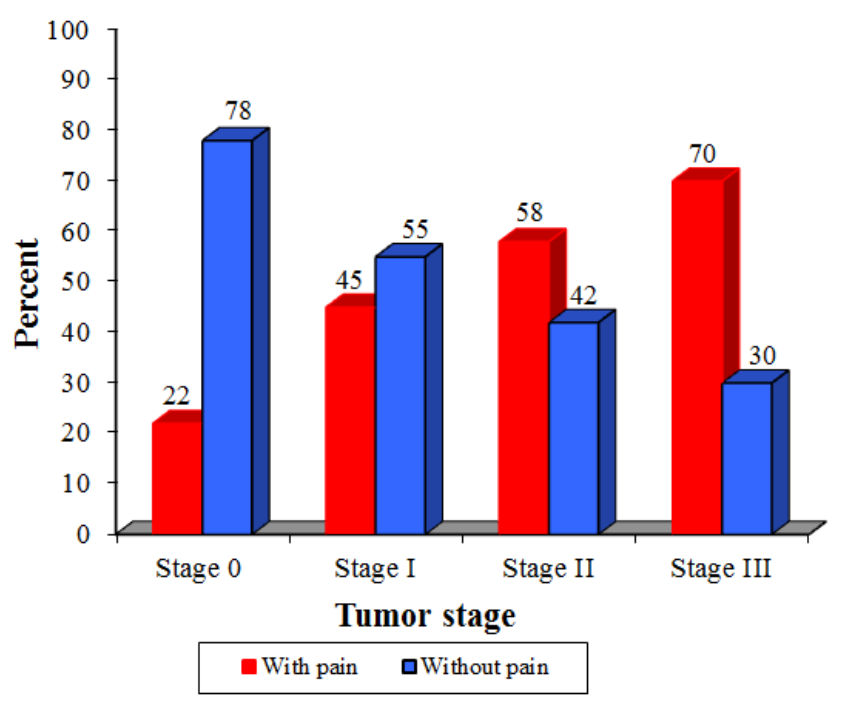

Figure 1. The incidence of PMPS with different tumor stages.

Fifty six out the studied 167 patients had undergone SLNB and only $23(41.1 \%)$ of them complain from chronic postoperative pain while $64(57.7 \%)$ out of the remaining 111 patients who underwent complete axillary dissection had PMPS. This finding denotes significant decrease in the incidence of PMPS with the SLNB group (Chi-2=4.10 \& Pvalue $=0.043)$. Out of the studied 167 women, $115(69 \%)$ had undergone modified radical mastectomy (MRM) while 52 patients $(31 \%)$ had undergone breast conserving therapy (BCT). Of the 87 women reporting persistent PMPS, 63 underwent MRM and only 24 underwent BCT (Chi-2=1.07 \& P-value $=0.301$ )

Patients who experienced pain are classified according to the nature of their pain into: phantom pain which is pain experienced in the breast that has been removed, intercostobrachial neuralgia which is pain and other sensory changes in the distribution of intercostobrachial nerve, neuroma pain which is scar pain that exacerbated by percussion and other nerve injury pain (medial and lateral pectoral, long thoracic, thoracodorsal nerves). Intercostobrachial neuralgia was the most commonly reported type of pain among patients underwent MRM and patients underwent BCT (Chi-2=10.47 \& P-value=0.015) (Table 3).

Table3. The relation between pain character and the type of surgery.

\begin{tabular}{llll}
\hline \multicolumn{1}{c}{ Type of surgery } & MRM 63 & BCT 24 & $\begin{array}{l}\text { Total } \\
\mathbf{8 7}(52 \%)\end{array}$ \\
\cline { 1 - 4 } Types of pain & $16(100 \%)$ & $0(0 \%)$ & $16(18,4 \%)$ \\
Phantom breast & $29(60 \%)$ & $19(40 \%)$ & $48(55 \%)$ \\
Intercostobrachial neuralgia & $16(76 \%)$ & $5(24 \%)$ & $21(24 \%)$ \\
Neuroma pain (scar pain) & $2(100 \%)$ & $0(0 \%)$ & $2(2,3 \%)$ \\
Other nerve injury pain & $2(10 \%)$ & \\
\hline
\end{tabular}

After measurement of the intensity of pain using VAS, the studied patients were classified into three groups according to pain intensity (mild 1-3, moderate4-6 and severe 7-10 on VAS) ${ }^{(22)}$. Moderate and severe pain were most commonly reported among patients underwent MRM while mild pain was most commonly reported among patients underwent
BCT $($ Chi-2=17.51 \& P-value=0.001) (Figure 2).

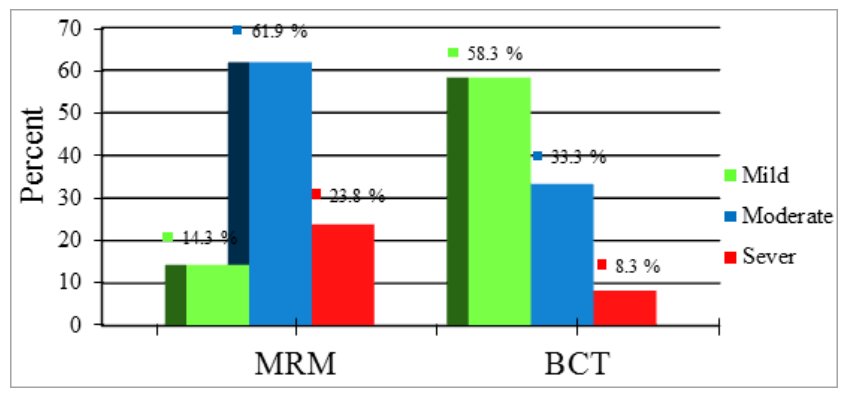

Figure 2. Pain intensity with MRM and BCT.

As regards the location of pain, many patients feel it in more than one site. The shoulder, axilla and arm complex was the most commonly reported site $(48.3 \%)$, while the upper anterior chest wall was the least reported site (13.8\%). Fifty four patients $(62 \%)$ out of the eighty seven patients who reported persistent PMPS mentioned certain factors that increase pain intensity (Table 4).

Table 4. Factors increasing pain after surgery for breast cancer.

\begin{tabular}{lll}
\hline Factors & No & \% \\
\hline Sleeping on the operated side & 12 & $22 \%$ \\
Touch & 2 & $4 \%$ \\
Walking & 1 & $2 \%$ \\
Carrying & 10 & $19 \%$ \\
Working with the arm & 10 & $19 \%$ \\
Getting up from bed & 5 & $9 \%$ \\
Changes in weather & 2 & $4 \%$ \\
\hline
\end{tabular}

\section{Discussion}

Although the techniques used in breast cancer surgery have improved dramatically in recent years, yet several complications still follow this type of surgery. In the present study, we focus on PMPS considering it an important complication that affect quality of life through the combined impact of physical disability and emotional distress ${ }^{(8)}$. Despite the literature is not precise when defining chronic pain after the surgical treatment of breast cancer ${ }^{(2)}$, we depend on the data obtained from (IASP) ${ }^{(7)}$ which define PMPS as pain persisting continuously or intermittently for more than three months after surgery.

Several trials with different sizes have investigated PMPS, leaving considerable doubt about the magnitude of the problem. PMPS has been shown to develop in $20-68 \%$ of patients ${ }^{(5,21)}$. However, even estimates at the lower end of these ranges suggest that the problem is considerable. The current study found a prevalence of $52 \%$. Variations in the reported estimates of the problem may be due to factors including variations of the length of time after surgery, type of the procedure, research method, pain assessment tools, and the distribution of various demographic and clinical characteristics of the studied populations.

There are many risk factors for PMPS, some related to the patient and others related to the surgery. Among patientrelated factors is the age of the patient. In the current study, 
we found that the frequency of PMPS decreased gradually with aging from being $75 \%$ in women aged (35-44) years to $26 \%$ in women aged (65-74) years. The young age is found a significant factor in increasing incidence of PMPS. Similarly; Katz J et al, ${ }^{(19)}$ stated that the incidence of PMPS is higher in younger patients. He explained this finding by the fact that patients with breast cancer younger than 35 years have a worse prognosis, both due to the aggressive nature of the tumor and the high rate of recurrence. Other theories tried to explain the reasons for the higher incidence of this syndrome in younger patients. Among them we can mention; increased nerve sensitivity; nature of the cancer in pre-menopausal women; lower sensitive threshold due to higher anxiety; greater surgical invasion in axillary dissection ${ }^{(16)}$.

Among surgery-related factors we can mention the type of surgery. PMPS can follow any type of surgery in the breast, even in the absence of breast cancer, such as breast reconstruction. However, this phenomenon is more frequently associated with mastectomy and axillary clearance and for this reason it is called PMPS ${ }^{(2,23,24)}$. In the present study, we compared between two types of procedures (MRM and $\mathrm{BCT}$ ) and two types of axillary management (complete axillary dissection and SLNB). We found significant decrease in the incidence of PMPS among patients underwent less invasive procedures (BCT and SLNB).

The role of SLNB on decreasing the incidence of PMPS has been proved by many researchers $(14,16,25)$. Some studies have gone into more details and count the number of excised LNs and relate it to the severity of pain ${ }^{(17)}$. In 2014; a large nationwide postal survey in Norway was performed on 832 women who received surgery for breast cancer. It found that combined treatment of radical mastectomy with axillary lymph node dissection is a major risk factor ${ }^{(26)}$. Conversely, other researchers like Belfer and his colleagues ${ }^{(27)}$ found that some surgery-related factors including surgical type and axillary node dissection were not significantly associated with PMPS

The intensity and character of pain are significantly related to the type of surgery being more sever in in patient undergoing MRM and axillary dissection. The higher incidence of intercostobrachial neuralgia in both MRM and BCT denotes that this type of pain is not related to the type of mastectomy, but to the approach to the axilla where the intercostobrachial nerve can be damaged ${ }^{(10,28,29)}$. Because of this fact, some authors believe that post-axillary dissection pain is probably a more appropriate name than the usual post-mastectomy pain for this syndrome (11). New researches find a more aggressive approach that appears more effective in reducing that type of neuropathic pain ${ }^{(30)}$.

In the current study, we found that most of the patients expressed pain at shoulder, axilla, and arm complex (48.3\%). This finding matches with that of other studies ${ }^{(8,13-15)}$. Activities such as sleeping on the operated side, carrying and general housework caused pain. Stretching movements were described as exacerbating pain, and exercise was difficult, although some women used exercise and physiotherapy in their treatment regimes. In conclusion; persistent PMPS remains a large problem facing cancer surgeons in the postoperative period. They should be aware of the surgeryrelated risk factors in this distressing condition and try to eliminate them whenever possible by choosing appropriate surgical techniques.

\section{References}

[1] Omar S, Khaled H, Gaafar R, Zekry AR, Eissa S, el-Khatib O. Breast cancer in Egypt: a review of disease presentation and detection strategies. East Mediterr Health J. 2003 May;9(3):448-63.

[2] Couceiro TC, Menezes TC, Valênça MM. Postmastectomy pain syndrome: the magnitude of the problem. Rev Bras Anestesiol. 2009 May-Jun;59(3):358-65.

[3] Kwekkeboom K. Postmastectomy pain syndromes. Cancer Nurs. 1996 Feb;19(1):37-43.

[4] Bokhari F, Sawatzky JA. Chronic neuropathic pain in women after breast cancer treatment. Pain ManagNurs. 2009 Dec;10(4):197-205.

[5] Vadivelu N, Schreck M, Lopez J, Kodumudi G, Narayan D. Pain after mastectomy and breast reconstruction. Am Surg. 2008 Apr;74(4):285-96.

[6] Wood KM. Intercostobrachial nerve entrapment syndrome. South Med J. 1978 Jun;71(6):662-3.

[7] International Association for the Study of Pain. Task Force on Taxonomy - Classification of Chronic Pain: descriptions of chronic pain syndromes and definition of pain terms, $2 \mathrm{Ed}$. Seattle, IASP Press 1994.

[8] Vilholm OJ, Cold S, Rasmussen L, Sindrup SH. The postmastectomy pain syndrome: an epidemiological study on the prevalence of chronic pain after surgery for breast cancer. Br J Cancer. 2008 Aug 19;99(4):604-10.

[9] Macdonald L, Bruce J, Scott NW, Smith WC, Chambers WA. Long-term follow-up of breast cancer survivors with postmastectomy painsyndrome. $\mathrm{Br}$ J Cancer. 2005 Jan 31;92(2):225-30.

[10] Jung BF, Ahrendt GM, Oaklander AL, Dworkin RH. Neuropathic pain following breast cancer surgery: proposed classification and research update. Pain. 2003 Jul;104(1-2):1-13.

[11] Vecht CJ, Van de Brand HJ, Wajer OJ. Postaxillary dissection pain in breast cancer due to a lesion of the intercostobrachial nerve. Pain. 1989 Aug;38(2):171-6.

[12] Blunt C, Schmiedel A. Some cases of severe post-mastectomy pain syndrome may be caused by an axillary haematoma. Pain. 2004 Apr;108(3):294-6.

[13] Meijuan Y, Zhiyou P, Yuwen T, Ying F, Xinzhong C. A retrospective study of postmastectomy pain syndrome: incidence, characteristics, risk factors, and influence on quality of life. ScientificWorldJournal. 2013 Nov 27;2013:159732

[14] Mejdahl MK, Andersen KG, Gärtner R, Kroman N, Kehlet H. Persistent pain and sensory disturbances after treatment for breast cancer: six year nationwide follow-up study. BMJ. 2013 Apr 11;346:f1865. 
[15] Carpenter JS, Sloan P, Andrykowski MA, McGrath P, Sloan D, Rexford T, Kenady D. Risk factors for pain after mastectomy/lumpectomy. Cancer Pract. 1999 MarApr;7(2):66-70.

[16] Gärtner R, Jensen MB, Nielsen J, Ewertz M, Kroman N, Kehlet H. Prevalence of and factors associated with persistent pain following breast cancer surgery. JAMA. 2009 Nov 11;302(18):1985-92

[17] AlvesNogueiraFabro E, Bergmann A, do Amaral E Silva B, PadulaRibeiro AC, de Souza Abrahão K, da Costa Leite Ferreira MG, de Almeida Dias R, Santos Thuler LC. Postmastectomy pain syndrome: incidence and risks. Breast. 2012 Jun;21(3):321-5.

[18] Poleshuck EL, Katz J, Andrus CH, Hogan LA, Jung BF, Kulick DI, Dworkin RH. Risk factors for chronic pain following breast cancer surgery: a prospective study. J Pain. 2006 Sep;7(9):626-34.

[19] Katz J, Poleshuck EL, Andrus CH, Hogan LA, Jung BF, Kulick DI, Dworkin RH. Risk factors for acute pain and its persistence following breast cancer surgery. Pain. $2005 \mathrm{Dec}$ 15;119(1-3):16-25. Epub 2005 Nov 17.

[20] Andersen KG, Kehlet H. Persistent pain after breast cancer treatment: a critical review of risk factors and strategies for prevention. J Pain. 2011 Jul;12(7):725-46.

[21] Ramesh, Shukla NK, Bhatnagar S. Phantom breast syndrome. Indian J Palliat Care. 2009 Jul;15(2):103-7.

[22] Myles P, Troedel S, Boquest M, Reeves M. The Pain Visual Analog Scale: Is It Linear or Nonlinear? AnesthAnalg. 1999;89:1517-20.

[23] Miaskowski C, Cooper B, Paul SM, West C, Langford D, Levine JD, Abrams G, Hamolsky D, Dunn L, Dodd M, Neuhaus J, Baggott C, Dhruva A, Schmidt B, Cataldo J, Merriman J, Aouizerat BE. Identification of patient subgroups and risk factors for persistent breast pain following breast cancer surgery. J Pain. 2012 Dec;13(12):1172-87.
[24] Schreiber KL, Martel MO, Shnol H, Shaffer JR, Greco C, Viray N, Taylor LN, McLaughlin M, Brufsky A, Ahrendt G, et al. Persistent pain in postmastectomy patients: comparison of psychophysical, medical, surgical, and psychosocial characteristics between patients with and without pain. Pain. 2013 May; 154(5):660-8.

[25] Miguel R, Kuhn AM, Shons AR, Dyches P, Ebert MD, Peltz ES, Nguyen K, Cox CE. The effect of sentinel node selective axillary lymphadenectomy on the incidence of postmastectomy pain syndrome. Cancer Control. 2001 SepOct;8(5):427-30.

[26] SchouBredal I, Smeby NA, Ottesen S, Warncke T, Schlichting E. Chronic Pain in Breast Cancer Survivors: Comparison of Psychosocial, Surgical, and Medical Characteristics Between Survivors With and Without Pain. J Pain Symptom Manage. 2014 Apr 2. pii: S0885-3924(14)00148-1

[27] Belfer I, Schreiber KL, Shaffer JR, Shnol H, Blaney K, Morando A, Englert D, Greco C, Brufsky A, Ahrendt G, KehletH,Edwards RR, Bovbjerg DH. Persistent postmastectomy pain in breast cancer survivors: analysis of clinical, demographic, and psychosocial factors. J Pain. 2013 Oct;14(10):1185-95.

[28] Hansen DM, Kehlet H, Gärtner R. Phantom breast sensations are frequent after mastectomy. Dan Med Bull. 2011 Apr;58(4):A4259.

[29] Steegers MA, Wolters B, Evers AW, Strobbe L, Wilder-Smith $\mathrm{OH}$. Effect of axillary lymph node dissection on prevalence and intensity of chronic and phantom pain after breast cancer surgery. J Pain. 2008 Sep;9(9):813-22.

[30] Chiu M, Bryson GL, Lui A, Watters JM, Taljaard M, Nathan HJ. Reducing persistent postoperative pain and disability 1 year after breast cancer surgery: a randomized, controlled trial comparing thoracic paravertebral block to local anesthetic infiltration. Ann Surg Oncol. 2014 Mar; 21(3):795-801 